\title{
Comparison of Sampling Methods Used to Estimate Spider (Araneae) Species Abundance and Composition in Grape Vineyards
}

\author{
MICHAEL J. COSTELLO ${ }^{1}$ AND KENT M. DAANE ${ }^{2}$ \\ Center for Biological Control, Department of Environmental Science, Policy and Management, \\ University of California, Berkeley, CA 94720
}

\begin{abstract}
Environ. Entomol. 26(2): 142-149 (1997)
ABSTRACT The effectiveness of 3 methods for sampling spiders in grape vineyards was tested. The sampling methods were as follows: (1) a drop-cloth method in which spiders were dislodged from a $5.1-\mathrm{m}^{2}$ area of grapevine onto a drop cloth, (2) a funnel method in which spiders were dislodged into a $0.74-\mathrm{m}^{2}$ funnel, and (3) a D-vac method in which 50 sections of grapevine $\left(30-\mathrm{cm}\right.$ sections, total area of $\left.5.4 \mathrm{~m}^{2}\right)$ were suctioned with a gasoline-powered vacuum. Data from all sampling methods were adjusted for area sampled and compared with an absolute control, in which foliage from an entire vine was removed and searched for spiders. Analyses were made on the following 8 most abundant spider species: Anyphaena pacifica Banks, Metaphidippus vitis (Cockerell), Theridion dilutum Levi and Theridion melanurum Hahn (grouped as Theridion spp.), Cheiracanthium inclusum (Hentz), Hololena nedra Chamberlin \& Ivie, Trachelas pacificus (Chamberlin \& Ivie), and Erigone dentosa (O.P.-Cambridge). Mean spider abundance from each sampling method differed significantly from the absolute control in $(\geq 1)$ species. The funnel method often overestimated spider abundance'while the drop-cloth and D-vac methods often underestimated spider abundance. Estimates of spider species composition were most accurately measured by the drop-cloth method and were significantly altered by the $D$-vac method. We tested 3 data transformations $(\ln [x+1], V[x+$ $0.5]$, and $\left.x^{1-b / 2}\right)$ to stabilize the variance and satisfy the requirements of analysis of variance (ANOVA). No single transformation uncoupled the mean and variance for all spider species over the 3 sampling methods. Using mean and variance of mean spider abundance, sample size and dispersion parameters were created by way of the Taylor power law. Sample sizes were determined for each sampling method; estimates of sample size and sampling costs varied considerably among spider species and sampling methods. All but 1 spider species collected with the drop-cloth method had a clumped distribution, the funnel method produced variable dispersion indexes, and all spider species collected with the D-vac method had a random distribution pattern. Whereas no single sampling method was best for all spider species, the funnel method is favored because of its efficiency in estimating spider densities and its reduced cost.
\end{abstract}

KEY WORDS spiders, grapes, sampling, vineyards

SPIDERS EXIST IN agroecosystems as a complex of species (LeSar and Unzicker 1978, Dean et al. 1982), with individual species having different biologies and behaviors, such as resting sites, diurnal rhythms, methods of prey capture, and degrees of mobility (Agnew and Smith 1989, Breene et al. 1993, Nyffeler et al. 1994). This diversity makes the development of a precise and cost-effective sampling program for spiders challenging. Some spiders, such as the Araneidae (orb weavers), have life habits conducive to sampling in situ by directly counting the number of web sites. However, only a portion of the spider species present in most

\footnotetext{
'Current address: University of California Cooperative Extension, 1720 South Maple, Fresno, CA 93702.

${ }^{2}$ Mailing address: Kearney Agricultural Center, 9240 South Riverbend, Parlier, CA 93648.
}

cropping systems have life habits that are so amenable to such direct sampling methods (Wheeler 1973; Nyffeler et al. 1986, 1988; Costello and Daane 1995). For example, many of the nocturnal hunters would be missed by a direct visual count. Sampling spiders in many perennial systems is made more difficult because of plant architecture, which can limit access to portions of the plant, and preclude use of some of the more common sampling methods such as sweep-netting (Howell and Pienkowski 1971, Wheeler 1973).

In California vineyards, spiders have been noted as one of the more abundant predators on grapevines, Vitis vinifera $\mathrm{L}$. (Cate 1975), and they may contribute to the natural control of some insect pests (Wilson et al. 1992, Coviello et al. 1992). However, there is relatively little information about 
the spider fauna in grape agroecosystems, resulting in the need to develop a sampling method to estimate spider species abundance and composition. Spiders may be sampled by visual counts of spiders and spider webs, beating the foliage to dislodge the spiders onto a drop cloth or into a funnel, or a D-vac suction device. Costello and Daane (1995) surveyed spiders in grape vineyards by shaking and beating spiders onto a drop cloth. Dietrick et al. (1959) first described the D-vac and its many uses as a nonspecific sampling tool for arthropods in agroecosystems. Spiders have been sampled in other perennial cropping systems using similar methods. Dondale et al. (1979) and McCaffrey et al. (1984) sampled spiders in apples, and Putman (1967) sampled spiders in peaches by beating tree limbs to dislodge spiders onto a cloth-covered tray. In citrus orchards, Mansour and Whitcomb (1986) dislodged spiders into a silk funnel, and Carroll (1980) collected spiders using a combination of observation, limb beating, and a D-vac. Here, we present results from field experiments that compared the effectiveness of drop cloth, funnel, and D-vac sampling methods as spider sampling tools.

\section{Materials and Methods}

The study was conducted in 1993 and 1994 at the University of Califormia, Kearney Agricultural Center in Parlier, CA. The vineyard used was a 35-yr-old, 0.81-ha 'Thompson Seedless' block on 3.3- $\mathrm{m}$ spacings between rows and $2.1 \mathrm{~m}$ within the row; the vines were cane-pruned and trained on a 61-cm crossbar (2 wire) trellis system. A cover crop consisting of $80 \%$ purple vetch, Vicia benghalensis L., and $20 \%$ common barley, Hordeum vulgare $\mathrm{L}$., was sown in October of each year at a seeding rate of $40 \mathrm{~kg} / \mathrm{ha}$. The cover crop was mowed in the spring of each year and replaced naturally by a summer complex of resident vegetation that included large crabgrass, Digitaria sanguinalis (L.) Scopoli; yellow foxtail, Setaria geniculata (Lam.) de Beauvois; and knotweed, Polygonum aviculare L. Three applications of sulfur were made to control powdery mildew, Uncinula necator Burrill. One application of sodium fluoroaluminate (Kryocide, Elf Atochem North America, Philadelphia, PA) was made to control the 2 lepidopteran pests: western grapeleaf skeletonizer, Harrisina brillians Barns \& McDunnough, and Platynota stultana Walshingham. Two applications of glyphosate (Roundup, Monsanto, St. Louis, MO) were made for in-row weed control.

Spider species abundance and composition, as estimated by the drop cloth, funnel, and D-vac sampling methods, were compared with an absolute control. For the drop-cloth method, a cloth was laid on the ground underneath 2 contiguous grapevines (sampling area $5.1 \mathrm{~m}^{2}$ ). The sampled grapevines were shaken by hand and their trunks beaten with mallets for $\approx 30 \mathrm{~s}$ to dislodge spiders. Spiders on the drop cloth were then collected with small battery-powered vacuums (Dustbuster, Black \& Decker, Towson, MD) that had the filter inside replaced with an organdy screen to collect live spiders. The collection procedure was repeated, and the total number of spiders collected from the 2 shakings constituted the sample. The funnel method used a cloth funnel which measured 0.86 by $0.86 \mathrm{~m}$ at the top and tapered to 0.1 by $0.1 \mathrm{~m}$ at the bottom. The top of the funnel was supported by a PVC pipe frame, creating a $0.74-\mathrm{m}^{2}$ sample area. The funnel was held under a section of foliage between 2 vines, and the fruiting canes above were shaken by hand and beaten with mallets for $\approx 30 \mathrm{~s}$ to dislodge spiders into the funnel. The D-vac method used a gasoline-powered blowervacuum with an intake rate of $8.42 \mathrm{~m}^{3} / \mathrm{min}$ (Echo, Lake Zurich, IL) fitted with an orifice $(30-\mathrm{cm}$ diameter) over which an organdy net was used to collect spiders. The $\mathrm{D}$-vac was thrust into the grapevine foliage at 2-m intervals of a grapevine row and left for $\approx 5 \mathrm{~s}$. A sample consisted of 50 thrusts (that were pooled as 1 sample), resulting in a $3.6-\mathrm{m}^{2}$ sample area. The 3 sampling methods were compared with an absolute control which involved collecting all vegetation from an entire grapevine, which was placed in 14.5-liter plastic bags.

All collected spiders were immediately placed into plastic bags, stored in ice chests (to retard spider metabolism and minimize predation), and transported to the laboratory where species were identified and enumerated. Samples were taken monthly from May to September in 1993 and 1994. The number of replicates varied for each sampling method because of variation in unadjusted sample area. There were $8,12,4$, and 4 samples taken on each sampling date for the drop cloth, funnel, D-vac, and absolute control, respectively. Sample rows were selected from every 4 th row in the vineyard and, within each sample row, sample vines were selected randomly.

Data Analysis. Unless noted otherwise, data were adjusted to a standard $2.54-\mathrm{m}^{2}$ sample area, which is the average 2-dimensional area covered by 1 grapevine. A split-plot design was used for all analyses, with sampling method as the main plot factor, study year as the subplot factor, and the monthly samples as replications. Thus, the main plot error was the sampling method $\times$ replicate interaction ( $\mathrm{df}=8$ ) and the subplot error was the sampling method $\times$ year $\times$ replicate $\times$ interaction $(\mathrm{d} f=12)$. The Kruskal-Wallis 1-way test was computed on ranked monthly means (Wilkinson 1992), and analysis of variance (ANOVA) was computed on variance/mean ratios for each of the sampling methods (PROC GLM, SAS Institute 1994). There was a significant sampling method $\times$ year interaction $(P=0.011)$ in the variance-mean ratio for Metaphidippus vitis Cockerell, and a significant sampling method $\times$ year interaction in monthly means for Theridion dilutum Levi and Theridion melanurum Hahn (grouped as Theridion spp.) ( $P$ 
$=0.027)$ and $M$. vitis $(P=0.032)$. For all other spider species, no significant sampling method $X$ year interactions were found, and data from both years were combined for these analyses.

Spider Species Abundance and Composition. For each sampling method, spider abundance was compared with the absolute control using the Dunnett $t$-test ( $P=0.05$ ) (PROC GLM, SAS Institute 1994). The accuracy with which each sampling method estimated spider abundance was compared by regressing the mean density of each spider species for each sampling method against the mean density for the absolute control for each sample date (data were transformed to $\log _{10}$ ) (PROC REG, SAS Institute 1994). Similarly, the degree to which each sampling method affected spider species composition was estimated by regressing the proportion of each spider species per sample against the proportion in the absolute control (PROC REG, SAS Institute 1994). For both regression analyses, the resulting slopes for the different sampling methods were compared by $t$-tests (Gomez and Gomez 1984) to estimate accuracy relative to the absolute control (i.e., a $t$-test with $P$ $<0.05$ indicated that a sampling method differed significantly from the control).

Data Transformation. ANOVA assumes that a variable has a normal distribution and that the mean and variance are unrelated (Southwood 1978). Because the distribution of arthropods is often aggregated and the mean is not independent of the variance, data must often be transformed to stabilize the variance if the ANOVA is to be valid (Southwood 1978). We tested the following 3 transformations: natural $\log (\ln [\mu+1]), V(\mu+$ $0.5)$, and Healy and Taylor's (1962) transformation $\left(x^{1-b / 2}\right.$, with $b$ coming from the Taylor power law). For each sampling method, data were adjusted to the standard $2.54-\mathrm{m}^{2}$ sample area before the three transformations were applied. From transformed data, variances were regressed on means, generating correlation coefficients that were compared with untransformed data.

Spider species abundances for each sampling method were ranked and compared using the Kruskal-Wallis 1-way test (Wilkinson 1992). Spider species proportions were arcsin-transformed and compared by ANOVA (PROC GLM, SAS Institute 1994).

Sample Size Estimates. The mean and variance of spider abundance for each sample date were used to generate dispersion parameters by way of the Taylor power law (Taylor 1961):

$$
s^{2}=a \mu^{\mathrm{b}}
$$

where $s^{2}$ is the variance, $a$ is a sampling parameter, $\mu$ is the mean, and $b$ is an aggregation parameter. Least-squares estimates of $a$ and $b$ were obtained by regressing $\ln \left(s^{2}\right)$ on $\ln (\mu)$. The resulting slopes for each sampling method were compared by $t$ tests (Gomez and Gomez 1984).
For each sampling method, the minimum sample size needed to estimate spider densities at a given level of precision was calculated using the following formula provided by Finch et al. (1975):

$$
\log n=\left(\log a-2 \log \mathbf{D}_{0}\right)-(2-b) \log x,
$$

where $n$ is the number of samples; $a$ and $b$ are the intercept and slope, respectively, generated from the Taylor power law; and $D_{0}$ is the fixed level of precision. We used a value of 0.2 for $D_{0}$ (estimated population density within $20 \%$ of the mean) to compare estimated sample sizes per year and costs among the 3 methods.

\section{Results and Discussion}

Spider Species Abundance and Composition. All analyses were made on the 8 most abundant spider species, which constituted $>90 \%$ of all spiders collected over 2 yr. These were as follows: Anyphaena pacifica Banks (Anyphaenidae), Hololena nedra Chamberlin \& Ivie (Agelinidae), Cheiracanthium inclusum (Hentz) (Clubionidae), Trachelas pacificus (Chamberlin \& Ivie) (Corinnidae), Erigone dentosa (O.P.-Cambridge) (Linyphiidae), Metaphidippus vitis (Cockerell) (Salticidae), Theridion dilutum Levi and Theridion melanurum Hahn (Theridiidae).

Sampling method had a significant effect $(P<$ 0.05 ) on mean density or proportion of every spider species at some point during the study (Table 1). Four groups each differed from the absolute control when sampled by the funnel method $(C$. inclusum, $H$. nedra, Theridion spp. [1993] and $E$ dentosa) or drop-cloth method (C. inclusum, $H$ nedra, Theridion spp. [1993] and $M$. vitis [1993]), but 6 groups differed significantly from the absolute control when sampled by D-vac (A. pacifica, M. vitis [1993], Theridion spp. [1993], C. inclusum, $H$. nedra, and T. pacificus). Spider density was more often than not overestimated using the funnel method, and always was underestimated using the drop cloth and D-vac methods. The funnel overestimated $C$. inclusum by 0.22 spiders per vine, $H$. nedra by 0.77 spiders per vine, and $E$. dentosa by 0.96 spiders per vine, but underestimated Theridion spp. (1993) by 1.23 spiders per vine (Table 1). The drop cloth method underestimated $M$. vitis (1993) by 2.93 spiders per vine, Theridion spp. (1993) by 3.14 spiders per vine, $C$. inclusum by 2.01 spiders per vine, and $H$. nedra by 1.37 spiders per vine, whereas the $D$-vac method underestimated $A$. pacifica by 4.90 spiders per vine, $M$. vitis (1993) by 2.93 spiders per vine, Theridion spp. (1993) by 3.31 spiders per vine, C. inclusum by 2.59 spiders per vine, $H$. nedra by 2.68 spiders per vine, and T. pacificus by 1.89 spiders per vine.

Regression analyses also indicated differences among sampling methods in their estimation of overall spider abundance compared with the ab- 
Table 1. Mean spider density \pm SEM for each sampling method during 1993 and 1994

\begin{tabular}{lllcc}
\hline \hline \multirow{2}{*}{ Spider species } & \multirow{2}{*}{ Control } & \multicolumn{3}{c}{ Sampling method } \\
\cline { 3 - 5 } & & Drop cloth & Funnel & D-vac \\
\hline Anyphaena pacifica & $6.25 \pm 1.02$ & $4.89 \pm 0.62$ & $14.17 \pm 2.72$ & $1.35 \pm 0.32^{*}$ \\
Metaphidipptss vitis (1993) & $4.30 \pm 0.61$ & $1.37 \pm 0.18^{*}$ & $5.45 \pm 1.01$ & $2.07 \pm 0.53^{*}$ \\
M. Eitis (1994) & $2.35 \pm 0.64$ & $1.21 \pm 0.14$ & $4.43 \pm 0.63$ & $1.48 \pm 0.28$ \\
Theridion spp. (1993) & $3.70 \pm 1.00$ & $0.56 \pm 0.12^{*}$ & $2.47 \pm 0.85^{*}$ & $0.39 \pm 0.18^{*}$ \\
Theridion spp. (1994) & $1.00 \pm 0.49$ & $0.46 \pm 0.12$ & $2.67 \pm 0.81$ & $0.07 \pm 0.04$ \\
Cheiracanthium inclustum & $2.93 \pm 0.53$ & $0.92 \pm 0.13^{*}$ & $3.15 \pm 0.55^{*}$ & $0.34 \pm 0.10^{*}$ \\
Hololena nedra & $2.86 \pm 0.38$ & $1.49 \pm 0.17^{*}$ & $3.63 \pm 0.45^{*}$ & $0.18 \pm 0.07^{*}$ \\
Trachelas pacificus & $2.28 \pm 0.46$ & $1.67 \pm 0.19$ & $5.48 \pm 0.73$ & $0.39 \pm 0.11^{*}$ \\
Erigone dentosa & $0.55 \pm 0.13$ & $0.33 \pm 0.05$ & $1.51 \pm 0.28^{*}$ & $0.81 \pm 0.21$ \\
\hline
\end{tabular}

For each spider species, means marked with asterisks differed significantly from the absolute control (Dunnett $t$-test, $P<0.05$ ). Data were adjusted to $2.54-\mathrm{m}^{2}$ sampling area, which is the average 2 -dimensional area under a single grapevine.

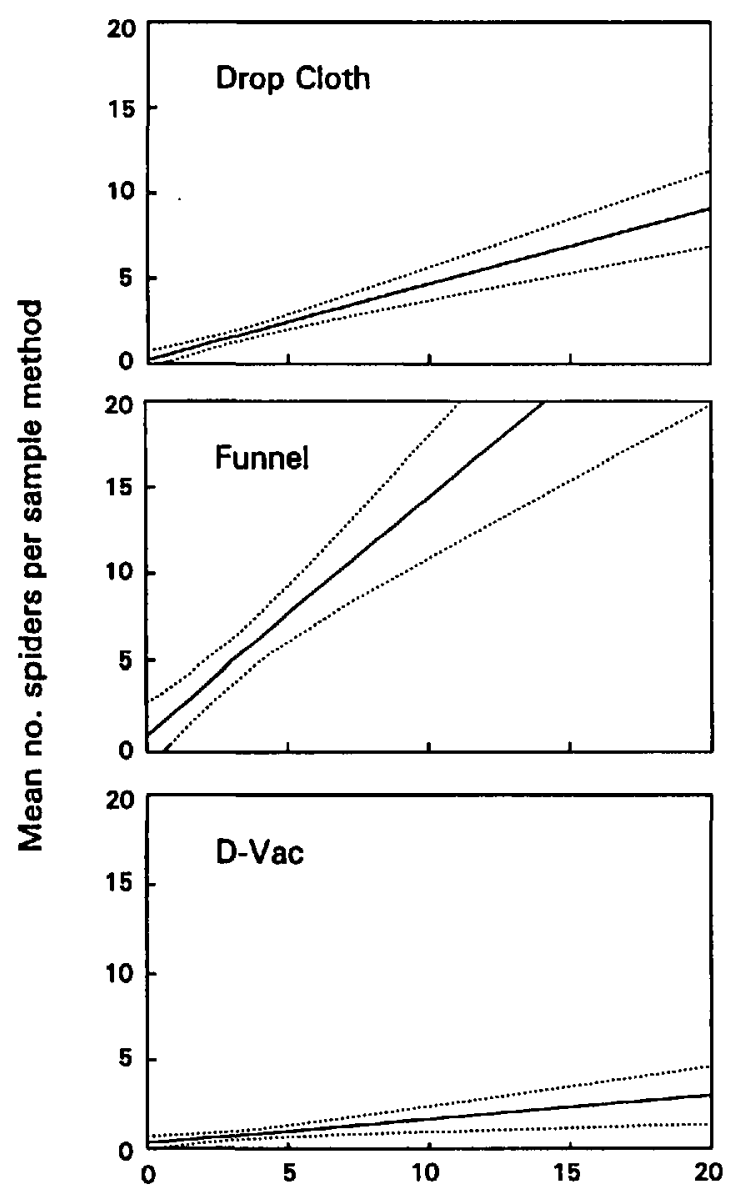

Mean no. spiders per control sample

Fig. 1. Regression of $\log _{10}$ spider species density by sampling date for each sampling method against the control. Dotted lines are $95 \%$ CI. Drop cloth: $y=0.24+$ $0.44 x ; F=48.0$, df $=1,68 ; P=0.0001, r^{2}=0.41$. Funnel: $y=0.89+1.35 x ; F=33.2, \mathrm{df}=1,68 ; P=$ $0.0001, r^{2}=0.32$. D-vac: $y=0.31+0.13 x ; F=8.1, \mathrm{df}$ $=1,61 ; P=0.006 ; r^{2}=0.10$. solute control (Fig. 1). The slope produced for the funnel method $\left(b=1.35, t=5.76, P=0.0001, r^{2}\right.$ $=0.318)$ was $>1$, indicating that this sampling method overestimated the density of the spider community by an average of $35 \%$ and suggests that spider distribution was aggregated between the vine trunks (the area sampled with the funnel method). Slopes produced for the drop cloth method $\left(b=0.44, \mathrm{t}=6.93, P=0.0001, r^{2}=\right.$ $0.405)$ and D-vac method $(b=0.13, t=2.85, P$ $=0.006, r^{2}=0.103$ ) underestimated spider density by an average of 56 and $87 \%$, respectively. Therefore, the funnel method is the most accurate method relative to the absolute control.

Sampling method also affected estimated values of spider species composition (Table 2). The D-vac collected a lower proportion of Theridion spp. (3.6\%) and a lower proportion of $H$. nedra (4.5\%) compared with the control (11.4 and $15.6 \%$, respectively), but collected a higher proportion of $M$. vitis $(30.6 \%)$ and $E$. dentosa (13.6\%) compared with the control (14.9 and $3.8 \%$, respectively) (Table 2). The funnel method was the only sampling method which did not differ from the absolute control with a species-by-species comparison. However, as indicated by regression analysis, overall spider species proportions were best estimated by the drop-cloth method (Fig. 2). Although there was a significantly positive relationship between the percentage of each spider species per sample regressed against the percentage in the absolute control for both the drop-cloth $\left(r^{2}=0.53, P<\right.$ $0.0001)$ and funnel methods $\left(r^{2}=0.40, P<\right.$ 0.0001 ), the drop cloth method estimated overall spider species composition most accurately. The slope for the drop cloth $(b=0.86)$ did not differ significantly from unity with the absolute control $\langle t$ $=1.43, \mathrm{df}=69, P>0.10$ ) whereas the slope for the funnel method $(b=0.69)$ was significantly different from $1(t=3.23, \mathrm{df}=69, P<0.01)$. There was no relationship between overall spider species proportions as sampled by the D-vac method and the absolute control (Fig. 2), indicating that the D-vac method significantly altered spider species composition compared with the control. 
Table 2. Mean spider proportion per sample \pm SEM for each sampling method during 1993 and 1994

\begin{tabular}{llccc}
\hline \multirow{2}{*}{ Spider species } & \multirow{3}{*}{ Control } & \multicolumn{3}{c}{ Sampling method } \\
\cline { 3 - 5 } & & Drop cloth & Funnel & D-vac \\
\hline Anyphaena pacifica & $0.432 \pm 0.05$ & $0.393 \pm 0.05$ & $0.253 \pm 0.07$ & $0.188 \pm 0.06$ \\
Metaphidippus vitis & $0.149 \pm 0.02$ & $0.142 \pm 0.02$ & $0.187 \pm 0.03$ & $0.306 \pm 0.05^{*}$ \\
Theridion spp. & $0.114 \pm 0.01$ & $0.057 \pm 0.01^{*}$ & $0.070 \pm 0.02$ & $0.036 \pm 0.02^{*}$ \\
Cheiracanthium inclusum & $0.121 \pm 0.02$ & $0.128 \pm 0.02$ & $0.198 \pm 0.05$ & $0.163 \pm 0.06$ \\
Hololena nedra & $0.156 \pm 0.02$ & $0.116 \pm 0.02$ & $0.144 \pm 0.04$ & $0.045 \pm 0.02^{*}$ \\
Trachelas pacificus & $0.101 \pm 0.02$ & $0.158 \pm 0.02$ & $0.196 \pm 0.03$ & $0.156 \pm 0.06$ \\
Erigone dentosa & $0.038 \pm 0.01$ & $0.019 \pm 0.01$ & $0.025 \pm 0.01$ & $0.136 \pm 0.05^{*}$ \\
\hline
\end{tabular}

For each spider species, means marked with asterisks differed significantly from the absolute control (Dunnett $t$-test, $P<0.05$ ).

Data Transformation. Data transformation was necessary for most spider species and sampling methods; the exceptions were the drop cloth samples for $T$. pacificus and $H$. nedra, funnel samples for Theridion spp. and $M$. vitis, and D-vac samples for $T$. pacificus (Table 3). In this test, a non signif-
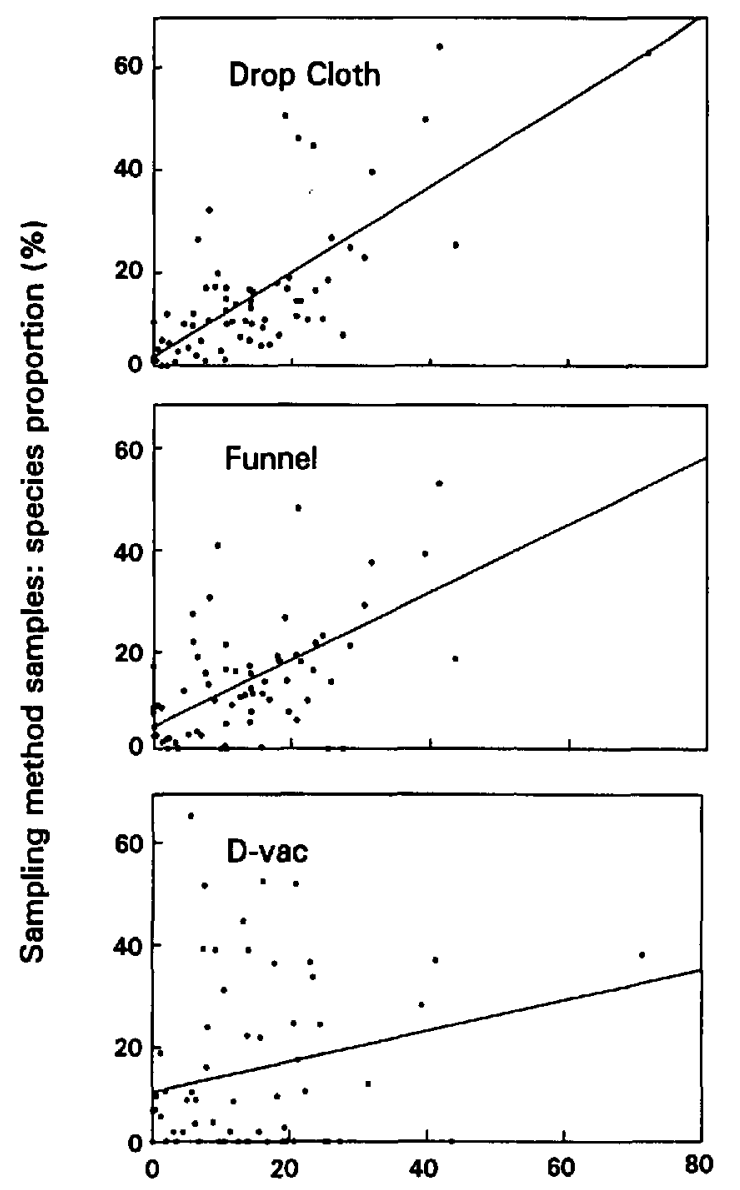

Control samples: species proportion (\%)

Fig. 2. Regression of spider species proportion (percentage of each species within each sample) by sampling date for each sampling method against the control. Drop cloth: $y=1.9+0.86 x ; F=79.8, \mathrm{df}=1,68 ; P=0.0001$, $r^{2}=0.54$. Funnel: $y=4.4+0.67 x, F=47.4, \mathrm{df}=1$, 68; $P=0.0001, r^{2}=0.41$. D-vac: $y=9.8+0.31 x, F=$ 3.2 , df $=1,61 ; P=0.767, r^{2}=0.06$. icant $P$ value indicates that means regressed against the variance were not correlated and the data transformation was successful. No single transformation was successful for all spider species and sampling methods, and for some species, only 1 specific combination of sampling method and transformation was successful (Table 3). For example, for A. pacifica, transformation proved successful for drop-cloth method data using a log transformation only. Similarly, for C. inclusum only the Healy \& Taylor transformation for the drop cloth method was successful. None of the 3 transformations successfully uncoupled Theridion spp. mean and variance.

Although significant correlations between variances and means for the original data indicate the need for data transformation, none of the common transformations could be used successfully for all spider species and sampling methods. If counts of a single spider species are to be analyzed in response to a particular treatment, care must be taken to select a transformation appropriate for the spider species and sampling method. The difficulty in finding a single transformation for all spiders suggests that nonparametric analyses should be used when comparing mean densities of different species.

Sample Size. Parameters generated by Taylor's power law indicate that mean/variance regressions were significant $(P<0.05)$ for all spider species in each sampling method, with the exception of Theridion spp. and $M$. vitis sampled by the funnel method (Table 4). The aggregation parameter (b) has been used to describe species distribution; values of $b>1$ indicate a clumped distribution, of $b$ $=1 \mathrm{a}$ random distribution, and of $b<1$ a uniform distribution (Taylor 1961). For the drop-cloth method, $b$ was significantly $>1$ for all species except $M$. vitis, indicating the distribution of each spider species is relatively clumped. With the funnel method, $b$ was significantly $>1$ for $C$. inclusum, T. pacificus, and A. pacifica only. For the D-vac method, $b$ did not differ significantly from 1 for any spider species, indicating a random spider species distribution, contrasting with results from the drop-cloth method.

The consistent finding of random distribution for $M$. vitis over all sampling methods reflects the 
Table 3. Correlation coefficients $\left(r^{2}\right)$ for the variance-mean relationship of original and transformed counts of selected spiders

\begin{tabular}{|c|c|c|c|c|c|}
\hline \multirow{2}{*}{ Spider species } & \multirow{2}{*}{ Sampling method } & \multirow{2}{*}{ Original counts } & \multicolumn{3}{|c|}{ Transformation } \\
\hline & & & $\ln (x+1)$ & $\sqrt{ }(x+0.5)$ & $\left(x^{1-b / 2}\right)$ \\
\hline \multirow[t]{3}{*}{ A. pacifica } & Drop cloth & $0.91^{*}$ & 0.05 & $0.78^{*}$ & $0.89 *$ \\
\hline & F unnel & $0.90^{*}$ & $0.84^{*}$ & $0.91 *$ & $0.95^{*}$ \\
\hline & D-vac & $0.75^{*}$ & $0.65^{*}$ & $0.70^{*}$ & $0.77^{*}$ \\
\hline \multirow[t]{3}{*}{ M. vitis } & Drop cloth & $0.81^{*}$ & 0.26 & 0.34 & $0.77 *$ \\
\hline & Funnel & 0.23 & 0.14 & 0.47 & $0.77^{*}$ \\
\hline & D-vac & $0.92^{*}$ & 0.43 & 0.20 & $0.84^{*}$ \\
\hline \multirow{3}{*}{ Theridion spp. } & Drop cloth & $0.83^{*}$ & $0.85^{*}$ & $0.84^{*}$ & $0.84^{*}$ \\
\hline & Funnel & 0.50 & $0.85^{*}$ & $0.85^{*}$ & $0.91 *$ \\
\hline & D-vac & $0.93^{*}$ & $0.88^{*}$ & $0.90^{*}$ & $0.95^{*}$ \\
\hline \multirow[t]{3}{*}{ C. inclusum } & Drop cloth & $0.98^{*}$ & $0.65^{*}$ & $0.88^{*}$ & 0.00 \\
\hline & Funnel & $0.91^{*}$ & $0.89^{*}$ & $0.91^{*}$ & $0.92^{*}$ \\
\hline & D-vac & $0.88^{*}$ & $0.96^{*}$ & $0.95^{*}$ & $0.89^{*}$ \\
\hline \multirow[t]{3}{*}{ H. nedra } & Drop cloth & 0.53 & 0.29 & 0.40 & 0.60 \\
\hline & Funnel & $0.78^{*}$ & $0.67^{*}$ & $0.76^{*}$ & $0.82^{*}$ \\
\hline & D-vac & $0.80^{*}$ & $0.74^{*}$ & $0.75^{*}$ & $0.73^{*}$ \\
\hline \multirow[t]{3}{*}{ T. pacificus } & Drop cloth & 0.53 & 0.30 & 0.43 & 0.62 \\
\hline & Funnel & $0.89^{*}$ & $0.83^{*}$ & $0.86 *$ & $0.91^{*}$ \\
\hline & D-vac & 0.52 & 0.40 & 0.44 & 0.53 \\
\hline
\end{tabular}

Data collected in 1993 and 1994 are combined; an asterisk indicates that the correlation between mean and variance is significant at $P<0.05$.

uniqueness of its behavior relative to the other spiders sampled. $M$. vitis is a diurnal hunting spider and often can be observed searching on the fringes of the canopy. Because of its mobile behavior, it is understandable that its distribution was random in the daylight morning hours when samples were collected. Had sampling occurred at night while $M$. vitis was resting, it may very well have had a more aggregated distribution. The nocturnal hunters (A. pacifica, C. inclusum, and $T$. pacificus) all had clumped distributions with the drop-cloth and funnel methods. This suggests that there are regions of the vine that are favored as resting sites for hunting spiders, and that these sites can be limiting within the vineyard.

The lack of a uniform distribution for any of these spider species is notable, especially for the sit-and-wait species (Theridion spp. and $H$. nedra). Spiders with such prey capture habits are territorial (Riechert and Lockley 1984) and would be expected to have a more even distribution. The clumped or random distribution patterns found in this study are most likely related to the sampling unit sizes used. Because territory is established within areas of favorable or preferable habitat, a sampling unit that closely approximates the size of the territory is more likely to reveal a uniform distribution (Wilson 1994). Indeed, values of $b$ were generally higher for the drop-cloth method, which sampled $5.1 \mathrm{~m}^{2}$ of sampling area versus the funnel method which sampled $0.74 \mathrm{~m}^{2}$. A still smaller sampling unit (e.g., a single leaf) may have revealed a uniform distribution for many of the spider species. Although the sampling unit was small-

Table 4. Taylor's power law parameters and corresponding regression statistics

\begin{tabular}{|c|c|c|c|c|c|}
\hline Sampling method & Spider species & $\ln a \pm S E M$ & $b \pm \mathrm{SEM}$ & $r^{2}$ & $P$ value \\
\hline \multirow[t]{6}{*}{ Drop cloth } & Anyphaena pacifica & $-1.60 \pm 0.77$ & $2.40 \pm 0.35^{*}$ & 0.84 & 0.0001 \\
\hline & Metaphidippus vitis & $-0.27 \pm 0.44$ & $1.35 \pm 0.35$ & 0.61 & 0.0046 \\
\hline & Theridion spp. & $-0.26 \pm 0.19$ & $1.94 \pm 0.24^{*}$ & 0.88 & 0.0001 \\
\hline & Cheiracanthium inchusum & $-0.02 \pm 0.11$ & $1.49 \pm 0.11^{*}$ & 0.95 & 0.0001 \\
\hline & Hololena nedra & $-0.25 \pm 0.56$ & $1.76 \pm 0.42^{*}$ & 0.65 & 0.0028 \\
\hline & Trachelas pacificus & $-0.16 \pm 0.36$ & $1.53 \pm 0.26^{*}$ & 0.79 & 0.0003 \\
\hline \multirow[t]{6}{*}{ Funnel } & Anyphaena pacifica & $-0.33 \pm 0.31$ & $1.97 \pm 0.21^{*}$ & 0.91 & 0.0001 \\
\hline & Metaphidippus titis & $0.44 \pm 0.35$ & $0.61 \pm 0.40$ & 0.12 & 0.1704 \\
\hline & Theridion spp. & $-0.01=0.40$ & $1.34 \pm 0.63$ & 0.28 & 0.0645 \\
\hline & Cheiracanthium inclusum & $0.03 \pm 0.11$ & $1.34 \pm 0.14^{*}$ & 0.91 & 0.0001 \\
\hline & Hololena nedra & $0.09 \pm 0.15$ & $1.11 \pm 0.20$ & 0.78 & 0.0004 \\
\hline & Trachelas pactificus & $-0.21 \pm 0.17$ & $1.65 \pm 0.17^{*}$ & 0.91 & 0.0001 \\
\hline \multirow[t]{6}{*}{ D-vac } & Antphaena pacifica & $-0.03 \pm 0.25$ & $1.23 \pm 0.22$ & 0.79 & 0.0007 \\
\hline & Metaphidippus vitis & $0.22 \pm 0.19$ & $1.09 \pm 0.17$ & 0.83 & 0.0003 \\
\hline & Theridion spp. & $0.02 \pm 0.04$ & $1.00 \pm 0.12$ & 0.90 & 0.0001 \\
\hline & Cheiracanthium inclusum & $-0.01 \pm 0.07$ & $1.17 \pm 0.14$ & 0.89 & 0.0001 \\
\hline & Hololena nedra & $-0.01 \pm 0.11$ & $1.40 \pm 0.32$ & 0.69 & 0.0031 \\
\hline & Trachelas pacificus & $0.03 \pm 0.16$ & $0.94 \pm 0.30$ & 0.54 & 0.0145 \\
\hline
\end{tabular}

For each spider species, estimates of $b$ marked with asterisks are significantly $>1$ ( $t$-test, $P<0.05$ ). 
Table 5. Seasonal spider density means (unadjusted for area sampled), estimated sample size, and estimated cost (as measured by sampling time) needed to estimate the mean with a precision level of 0.2

\begin{tabular}{|c|c|c|c|c|}
\hline Sampling method & Spider species & Sample mean & Sample size & Sampling time in $\mathrm{min}^{\circ}$ \\
\hline \multirow[t]{6}{*}{ Drop cloth } & Anyphaena pacifica & 9.10 & 13 & $735 \pm 110$ \\
\hline & Metaphidippus vitis & 2.58 & 11 & $621 \pm 93$ \\
\hline & Theridion spp. & 1.01 & 20 & $1,130 \pm 170$ \\
\hline & Cheiracanthitum inclusum & 1.96 & 18 & $1,034 \pm 170$ \\
\hline & Hololena nedra & 2.93 & 16 & $904 \pm 136$ \\
\hline & Trachelas pacificus & 3.30 & 13 & $734 \pm 110$ \\
\hline \multirow[t]{6}{*}{ Funnel } & Anyphaena pacifica & 3.75 & 18 & $630 \pm 90$ \\
\hline & Metaphidipptss vitis & 1.45 & 24 & $840 \pm 120$ \\
\hline & Theridion spp. & 0.76 & 30 & $1,050 \pm 150$ \\
\hline & Cheiracanthitum inclusum & 1.01 & 26 & $910 \pm 130$ \\
\hline & Hololena nedra & 1.10 & 26 & $910 \pm 130$ \\
\hline & Trachelas pacificus & 1.66 & 17 & $595 \pm 85$ \\
\hline \multirow[t]{6}{*}{ D-vac } & Anyphaena pacifica & 2.13 & 14 & $231 \pm 49$ \\
\hline & Metaphidippus vitis & 2.51 & 14 & $231 \pm 49$ \\
\hline & Theridion spp. & 0.33 & 78 & $1,287 \pm 273$ \\
\hline & Cheiracanthium inclusum & 0.56 & 41 & $676 \pm 143$ \\
\hline & Hololena nedra & 0.29 & 53 & $875 \pm 185$ \\
\hline & Trachelas pacificus & 0.64 & 42 & $693 \pm 147$ \\
\hline
\end{tabular}

n Variation in estimated time was caused by sampling personnel and vineyard conditions. The following time-range estimates (in min) were used: drop cloth 40-50 collect, 8-15 sort; funnel 10 collect, $20-30$ sort; D-vac 5 collect, 8-15 sort.

est for the $D$-vac method $\left(0.07 \mathrm{~m}^{2}\right)$, the random dispersion patterns found were influenced by pooling 50 subsamples, which were taken at $2-\mathrm{m}$ intervals of a grapevine row. Thus, the pooled sample was spread over $\approx 100 \mathrm{~m}$. A more important factor is the sampling limitations of the D-vac, which include a lack of sufficient air flow to pick up some spider species such as $H$. nedra, leading to a bias toward small (e.g., E. dentosa) or mobile (e.g., $M$. vitis) spiders, and engine noise and vine vibration that probably causes many individual spiders to retreat deeper into the canopy.

Estimations of sample sizes and costs based on unadjusted seasonal spider means are presented in Table 5. The range of sampling costs for the $3 \mathrm{sam}$ pling methods varied greatly among spider species. Therefore, which method is the most efficient depends upon the importance of each spider species in the research objectives. If only 1 spider is of interest, then choosing the most cost-effective sampling method is a matter of choosing the sampling method with the lowest estimated cost in minutes. Clearly, for $M$. vitis or A. pacifica, the $D$-vac would be the sampling method of choice. For the other spiders, the choice is less obvious and depends on the speed at which samples can be taken or processed, or both. For the drop-cloth method, this depends greatly upon spider density (i.e., more spiders on the drop cloth require greater time to collect and process). The major advantage of the funnel method is the greatly reduced field time (8-10 person-minutes versus $40-50$ person-minutes for the drop-cloth method), which allows more vineyards to be sampled within a given amount of time. Field collection times for the funnel and D-vac methods are fixed, but processing time varies with respect to the amount of extraneous material (flower parts, leaves, stems, grape berries, etc.) from which the spiders need to be sorted in the laboratory. Estimates of sampling costs among the remaining spiders overlap among the 3 methods, but the lowest cost estimates were found with the D-vac for M. vitis, C. inclusum, and A. pacifica, and with the funnel method for T. pacificus and Theridion spp. (Table 5).

We conclude that there is little in favor of using the D-vac method except in the very specialized case of evaluating the effect of a treatment on a single species such as $M$. vitis or $A$. pacifica. Each of the other 2 sampling methods would be acceptable either to survey vineyards for spider density and species proportion analyses or to evaluate specific treatment impacts on spider densities (e.g., insecticide trials, cultural practices). Overall, we favor the funnel method because of its greater efficiency in estimating overall spider species densities. Although the drop-cloth and funnel methods are similar in terms of overall cost, the funnel method reduces field time considerably compared with the drop cloth method, which enables more vineyards to be sampled on a given day.

\section{Acknowledgments}

Field and laboratory assistance was provided by Amanda Bird, Eric Davidian, Gunner Fossen, Dean Greenwood, Ross Jones, Harlan North, Victor Quijano and Glenn Yokota. Shanthi Kappagoda and Nicole Korfanta reviewed an early draft of the manuscript and their suggestions are greatly appreciated. We gratefully acknowledge the financial support of the California Table Grape Commission, Lodi-Woodbridge Winegrape Commission, UC Statewide IPM Project, and the UC Sustainable Agriculture Research and Education Project.

\section{References Cited}

Agnew, C. W., and J. W. Smith, Jr. 1989. Ecology of spiders (Araneae) in a peanut agroecosystem. Environ. Entomol. 18: 30-42. 
Breene, R. G., D. A. Dean, M. Nyffeler, and G. B. Edwards. 1993. Biology, predation ecology and significance of spiders in Texas cotton ecosystems with a key to the species. Tex. Ag. Exp. Stn. Bull. 1711.

Carroll, D. P. 1980 . Biological notes on the spiders of some citrus groves in central and southern California. Entomol. News 91: 147-154.

Cate, J. R. 1975. Ecology of Erythroneura elegantula Osborn (Homoptera: Cicadellidae) in grape agroecosystems in California. Ph.D. dissertation, University of California, Berkeley.

Costello, M. J., and K. M. Daane. 1995. Spider (Araneae) species composition and seasonal abundance in San Joaquin Valley grape vineyards. Environ. Entomol. 24: 823-8.31.

Coviello, R., D. L. Hirschfelt, and W. W. Barnett. 1992. Omnivorous leafroller, pp. 166-173. In D. L. Flaherty, L. P. Christensen. W. T. Lanini, J. J. Marois, P. A. Phillips, and L. T. Wilson [eds.], Grape pest management. University of California Division of Agriculture and Natural Resources Publication 3343, Berkeley, CA.

Dean, D. A., W. L. Sterling, and N. V. Horner. 1982. Spiders in eastern Texas cotton fields. J. Arachnol. 10: 251-260.

Dietrick, E. J., E. I. Schlinger, and R. Bosch. 1959. A new method for sampling arthropods using a suction collecting machine and modified Berlese funnel separator. J. Econ. Entomol. 52: 1085-1091.

Dondale, C. D., B. Parent, and D. Pitre. 1979. A 6-year study of spiders (Araneae) in a Quebec apple orchard. Can. Entomol. 111: 377-390.

Finch, S., G. Skinner, and G. H. Freeman. 1975. The distribution and analysis of cabbage root fly egg populations. Ann. Appl. Biol. 79: 1-18.

Gomez, K. A., and A. A. Gomez. 1984. Statistical procedures for agricultural research. Wiley, New York.

Healy, M.J.R., and L. R. Taylor. 1962. Tables for power-law transformations. Biometrika 49: 557-559.

Howell, J. O., and R. L. Pienkowski. 1971. Spider populations in alfalfa, with notes on spider prey and effect on harvest. J. Econ. Entomol. 64: 163-168.

LeSar, C. D., and J. D. Unzicker. 1978. Soybean spiders: species composition, population densities and vertical distribution. Ill. Nat. Hist. Surv. Biol. Notes 107.

Mansour, F., and W. H. Whitcomb. 1986. The spiders of a citrus grove in Israel and their role as biocontrol agents of Ceroplastes floridensis (Homoptera: Coccidae). Entomophaga 31: 269-276.
MeCaffrey, J. P., M. P. Parrella, and R. L. Horsburgh. 1984. Evaluation of the limb-beating sampling method for estimating spider (Araneae) populations on apple trees. J. Arachnol. 11: 363-368.

Nyffeler, M., D. A. Dean, and W. L. Sterling. 1986. Feeding habits of the spiders Cyclosa turbinata (Walckenaer) and Lycosa rabida Walckenaer. Southwest Entomol. 11: 195-201.

1988. Prey records of the web-building spiders Dictyna segregata (Dictynidae), Theridion australe (Theridiidae), Tidarren haemorrhoidale (Theridiidae), and Frontinella pyramitela (Linyphiidae) in a cotton agroecosystem. Southwest. Entomol. 33: 215-218.

Nyffeler, M., W. L. Sterling, and D. A. Dean. 1994. How spiders make a living. Environ. Entomol. 23: 1357-1367.

Putman, W. L. 1967. Prevalence of spiders and their importance as predators in Ontario peach orchards. Can. Entomol. 99: 160-170.

Riechert, S. E., and T. Lockley. 1984. Spiders as biological control agents. Annu, Rev. Entomol. 29: 299320.

SAS Institute. 1994. SAS/STAT user's guide: statistics, version 6.1. SAS Institute, Cary, NC.

Southwood, T.R.E. 1978. Ecological methods with particular reference to the study of insect populations. Wiley, New York.

Taylor, L. R. 1961. Aggregation, variance, and the mean. Nature (Lond.) 189: 732-735.

Wheeler, A. G. 1973. Studies on the arthropod fauna of alfalfa. V. Spiders (Araneida). Can. Entomol. 105: 425-432.

Wilkinson, L. 1992. SYSTAT: the system for statistics. SYSTAT, Evanston, IL.

Wilson, L. T. 1994. Estimating abundance, impact, and interactions among arthropods in cotton agroecosystems, pp. 475-514. In L. P. Pedigo and G. D. Buntin [eds.], Handbook of sampling methods for arthropods in agriculture. CRC, Boca Raton, FL.

Wilson, L. T., D. L. Flaherty, and W. L. Peacock. 1992. Grape leafhopper, pp. 140-152. In D. L. Flaherty, L. P. Christensen. W. T. Lanini, J. J. Marois, P. A. Phillips, and L. T. Wilson [eds.], Grape pest management. University of California Division of Agriculture and Natural Resources Publication 3343, Berkeley, CA.

Received for publication 1 March 1996; accepted 16 September 1996. 